\title{
Reduced fitness of Daphnia magna fed a Bt-transgenic
}

\section{maize variety}

Thomas Bøhn $\uparrow$, Raul Primicerio †, Dag O. Hessen $\S$ and Terje Traavik $\uparrow, \|$

$\dagger$ GenØk - Centre for Biosafety, The Science Park, P.O. box 6418, 9294 Troms $\varnothing$, Norway. Email: thomas@genok.org. Phone: +4777644541. Fax: +4777646100

$\$$ Norwegian College of Fishery Science, University of Troms $\emptyset$, N-9037 Troms $\emptyset$, Norway.

$\S$ Department of Biology, University of Oslo.

|| Department of Microbiology and Virology, School of Medicine, University of Troms $\emptyset$.

\section{Abstract}

Genetically modified (GM) maize expressing the Bt-toxin Cry1Ab (Bt-maize) was tested for effects on survival, growth and reproduction of the water flea Daphnia magna, a crustacean arthropod commonly used as model organism in ecotoxicological studies. In three repeated experiments, D. magna were fed $100 \%$ ground maize in suspension, using either GM or isogenic unmodified (UM) maize. D. magna fed GM-maize showed a significantly reduced fitness performance: the mortality was higher, a lower proportion of females reached sexual maturation and the overall egg production was lower compared to D. magna fed UM isogenic maize. We conclude that the tested variety of Bt-maize and its UM counterpart do not have the same quality as food sources for this widely used model organism. The combination of a reduced fitness performance combined with earlier onset of reproduction of D. magna fed Btmaize indicates a toxic effect rather than a lower nutritional value of the GM-maize.

Keywords: genetic engineering, life history, ecotoxicology, fitness, Bt-toxin, Cry1 Ab 


\section{Introduction}

A few herbivore insect species are considered important pests of major crop plants. These pests are targeted with genetic engineering by insertion of various Bacillus thuringiensis (Bt) cry genes. In the plant, these genes express Cry proteins with toxic effects on different target pest insects. The Cry1 Ab protein is the most widely used toxin against the Lepidoptera family. The most commonly Cry1 Ab transgenic plants, known as Bt-plants, are maize, rice, cotton and potato. In maize, the most frequent modifications include insect resistance (Bt), herbicide tolerance or the stacking of genes that provide both these traits. Insect resistant Btmaize contribute to more than $50 \%$ of the transgenic maize grown globally, but the use of varieties with stacked genes are increasing (James 2006).

The purpose of Bt-plants is to selectively kill insect pest species, thereby increasing plant yield without affecting other (non-target) species. For the environment, the purported selectivity and localized effect of Bt-plants may be an improvement over the use of sprayed pesticides. According to the US Environmental Protection Agency, Bt-crops pose no significant risk to the environment or to human health (Mendelson et al. 2003). However, the specificity of Bt-plant defence has yet to be established (Dutton et al. 2003, Dutton et al. 2005), especially since the mode of action of Cry proteins, both in target and non-target organisms, is not fully understood (Brandt et al. 2004, Crickmore 2005, Hilbeck and Schmidt 2006, Bravo et al. 2007).

Many non-target organisms, including herbivores, pollinators, parasitoids and predators will directly and indirectly be exposed to transgene products and altered interactions (Hilbeck 2001, Groot and Dicke 2002, Dutton et al. 2003, Andow and Hilbeck 2004, O'Callaghan et al. 2005) and it is well justified to test these for potential harmful effects. Several reviews cover 
many groups of invertebrates, but nearly all of the tested species are terrestrial. However, a large number of studies show significant negative impacts on non-target species after feeding transgenic plant parts. Without a clear mode of action of Cry1 Ab on non-target groups and negative effects found on predators (about $30 \%$ of the studies) and parasitoids (57\% of the studies) (Lövei and Arpaia 2005) and on about $50 \%$ of all studies of Bt-plants (Hilbeck and Schmidt 2006), there is a need for further studies of non-target organisms: which species are exposed, which are sensitive, what is/are the mode(s) of action, and ultimately: what are the consequences?

The list of non-target groups extends if we include aquatic ecosystems adjacent to agricultural fields. These receive run-off material from agricultural fields and harbour non-target organisms that are potentially exposed and affected by Bt-plants. The aquatic component of non-target organisms has received little attention. However, transgenic crylA $b$ genes have recently been shown to drain, persist and possibly be transported long distances into aquatic freshwater ecosystems from agricultural fields with GM Bt-maize (Douville et al. 2007). Douville and colleagues concluded that the crylAb transgene is likely to be expressed in aquatic environments, and recommended further monitoring strategies to characterize environmental exposure and effects. Rosi-Marshall and co-workers (2007) demonstrated that toxin-containing crop byproducts are dispersed, decomposed and consumed in aquatic environments adjacent to agricultural fields. They also demonstrated negative effect of Btplants on two non-target stream insects (caddisflies). Negative effects of released Bt-crop byproducts to aquatic environments have broad implications because such effects have been overlooked by previous research and management (Rosi-Marshall et al. 2007). 
The uncertainties, and lack of relevant research related to biological effects of Cry1 Ab plant versions, were reflected by a recent review concerning putative health effects of GM-plants. The author concluded with the question: "where is the scientific evidence showing that GM plants/food are toxicologically safe?" (Domingo 2007).

Daphnia magna is a crustacean (phylum Arthropoda) invertebrate that inhabits ponds and lakes in most regions of the world. It is a common inhabitant of ponds in agricultural landscapes, and will, like many other zooplankton and benthic arthropods, receive pollen and detritus from drainage water from agricultural fields (cf. Rosi-Marshall et al. 2007). D. magna feed non-selectively on a broad range of particles in the size range $1-50 \mu \mathrm{m}$, and where transgenic Bt-plants are grown, they may receive this is their diet in the form of detrital particles and pollen. The clonal D. magna is commonly used in toxicological and ecotoxicological research (Barry 1996, Atienzar et al. 2001, Kramer et al. 2004), and has shown no treatment-related adverse effects to acute toxicity tests on transgenic Cry1 Ab-maize pollen (Mendelson et al. 2003). However, a 48 hour acute toxicity is only a first step in testing a GM crop plant since sub-lethal effects are precluded. We analyse in detail the performance of D. magna feeding on transgenic Cry1Ab-maize, over the whole life-cycle. More accurate assessment including potential fitness costs can be derived from analysis of life history traits responses, i.e. responses on survival, growth and reproduction. The rapid life cycle of $D$. magna, combined with a predominant asexual mode of reproduction and minimal genetic variation as well as easily measurable and plastic life history traits, makes it an ideal model organism. Different species of the genus Daphnia have been used to evaluate not only pesticides, other toxicants and pharmaceuticals (Nogueira et al. 2004), but recently also for investigating the role of toxins in human disease (Campbell et al. 2004). To increase precision and level of detail in studies of responses, ecotoxicologists have started to include sub-lethal 
effects by using life histories and population fitness measures (Stark and Banks 2003). We transfer parts of this methodology to test comparatively the food quality of a GM versus the unmodified (UM) plant.

In the present study, we investigate whether Bt-maize may have negative impacts on a nontarget model organism, either by toxic effects or by reduced energy availability. We compare the fitness performance of D. magna that were fed either a variety of transgenic Cry $1 \mathrm{Ab}$ maize or its UM isogenic counterpart grown in the same environment. The measured response variables were: i) survival, ii) growth, iii) individual fecundity, iv) population fecundity, v) frequency of maturation and vi) age at maturation. We followed these response variables in three consecutive experiments, employing the same study design through the whole life cycle of the animals.

\section{Methods}

\section{Feed}

The transgenic Cry1Ab-maize was of the variety Dekalb 818 YG (a hybrid of MON 810) and a Philippine, local variety of maize called Dekalb 818. Both varieties (Dekalb 818 YG and Dekalb 818) were grown side by side in adjacent fields, divided by a small river, in Elizabeth Cruzara, near Iloilo City in 2003. Maize had been grown on these fields for many years. This was the very first year of GM-maize cultivation. The neighboring farmers delivering the GM and UM-maize have stated that there was no external pesticides used in the fields. We inspected the fields and confirmed their GM and UM status by PCR analyses of fieldcollected samples before buying the adequate maize amounts from local farmers. The 
transgenic status of the MON810 event was further verified by DNA nucleotide sequencing, employing an Applied Biosystems 3130xl genetic analyzer (data not shown).

We sub-sampled a $50 \mathrm{~kg}$ bag of GM-maize and analysed the expression of the $c r y 1 A b$ gene with ELISA on 15 samples from the bag (diluted 1:20-1:33), using a commercially available kit (Abraxis, www.abraxiskits.com). On average, the GM-maize expressed 67 (+/- 27 s.d) ng Cry1 Ab toxin per gram of dried grain tissue. All negative controls and the UM-maize showed negative results.

Maize feed were made twice (referred to as feed 1 and feed 2) from the same bag of kernels. Sub-samples of GM and UM-maize were drawn from $50 \mathrm{~kg}$ bags, and 35 grams of dried kernels were grinded with separate coffee-grinders (Petra Espresso), first on the coarsest grinding and then five times repeatedly on the finest setting. The resulting flour was sieved through a filter with $250 \mu \mathrm{m}$ mesh size. $800 \mathrm{mg}$ of the filtered maize flour were added to 250 ml of Aarchnia Daphnien Medium (ADAM) (Kluttgen et al. 1994), homogenized and frozen in $10 \mathrm{ml}$ test tubes. This is later referred to as the feed. All steps of the feed production were the same for GM and UM-maize.

In culture, Daphnia magna is generally raised on phytoplankton, but it may, like most zooplankton species, feed on a mixed diet of small particles. In the feeding trials we chose food concentrations within a range that is normally encountered in nature $\left(<10 \mathrm{mg} \mathrm{C}^{-1}\right)$, and both the control and the Bt-maize tests were conducted with the same concentrations to avoid food quantity effects. The size spectrum of both food types was analyzed with FacsCalibur flow-cytometer using $0.5 \mu \mathrm{m}$ beads as standard. These analyses revealed an almost identical 
particle size range for the Bt-maize and the control spanning $2-4 \mu \mathrm{m}$, which is close to optimal size range both for juvenile and adult D. magna.

In preliminary experiments, we had established that on a diet of $100 \%$ unmodified maize, $D$. magna had a survival close to $80 \%$ in 20 days, grew up to about $3 \mathrm{~mm}$ in body length (about 20-30\% smaller than on standard algal diet - e.g. Scenedesmus gracilis), and reproduced up to a maximum of six clutches within 42 days. The clutch sizes were small and within the range of one to four eggs. We did not follow the survival of the neonates, but used numbers of eggs as the reproductive endpoint in the study. With maize as the only food source, we eliminate any potential confounding effects associated with a composite diet.

\section{Experimental set-up}

All individuals of D. magna used in the experiments were born within 30 hours from the third clutch of a single clonal population. Twenty juvenile individuals were randomly chosen and assigned to separate glasses with $60 \mathrm{ml}$ autoclaved ADAM medium. Ten animals received the GM feed (treatment) and ten the UM feed (control) under identical environmental conditions in a climate chamber at $20^{\circ} \mathrm{C}$ and $24 \mathrm{~h}$ daylight (resembling the summer conditions at our latitude). Every third day, all individuals were transferred to new glasses with new medium using a broad tipped pipette. Thereafter, the position of each individual was re-randomized. Each D. magna was fed daily and inspected for survival and number of eggs produced. The experiment lasted for 42 days. Care was taken to provide the same amount of food for all experimental units within and among GM and UM food recipients. All individual D. magna were fed daily with $100 \mu \mathrm{l}$ of maize feed, corresponding to $0.4 \mathrm{mg}$ dry weight of maize or about $0.2 \mathrm{mg} \mathrm{C}$ per individual per day, i.e. within the range recommended for laboratory experiments with Daphnia (Sims et al. 1993). Our experiments combined the study of 
survival (ecotoxicological approach) with growth and fecundity (feeding performance approach) to be able to estimate the overall fitness implications of the GM treatment diet.

This experimental set-up was performed consecutively three times, hereafter referred to as experiment 1, 2 and 3. Feed 1 was used in experiment 1, and feed 2 in experiments 2 and 3. The same clonal line of D. magna was used in all experiments.

\section{Measurements}

Body length was measured 17, 29 and 42 days after the experiment was initiated. In experiment 1 , individual D. magna from both groups (GM treatment and UM control) were measured for body length (distance from the top of the head to the base of the caudal spine) using a 40x binocular microscope. In experiment 2 and 3 body length was measured by image analysis (using ImageJ software) based on digital photographs of D. magna individuals. All length measurements were done "double blind', i.e. the observer (and the experimental unit, the D. magna) did not know to which group the measured individual belonged.

\section{Statistical analysis}

\section{Survival}

Statistical calculations were performed in R (2.5.0) and Systat (10.2) software. Survival analyses were performed in R using the package 'survival' and Cox proportional hazards (coxph test) for testing differences between GM and UM groups. For estimating the predicted mean survival we used a survival-model based on the survreg-function in R, with exponential error terms specified.

\section{Growth and reproduction}


In $t$-tests (within each experiment) we used pooled variances. Since the variability was relatively high among experiments, we analyzed overall differences (all experiments combined) with Experiment as a covariate (ANCOVA), i.e. correcting for differences between the experiments. The analyses on fecundity were based on ln-transformed numbers of eggs. The percentage of females that reached maturation was tested with Chi-square tests. The age at $50 \%$ maturation was estimated with logistic regression and the confidence limits were calculated with bootstrapping in R using the package 'boot' with 1000 re-samplings including bias correction and acceleration. 


\section{Results}

\section{Survival}

D. magna had reduced survival when fed GM-maize compared with UM-maize (Fig. 1 and

Fig. 2). The difference was statistically significant in experiment $1(\boldsymbol{p}=\mathbf{0 . 0 3 1}$, coxph test $)$ and in the combined data from all experiments $(\boldsymbol{p}=\mathbf{0 . 0 2 9}$, coxph test $)$. The predicted mean survival was lower in D. magna fed GM-maize (mean survival for pooled data: UM 45 days, GM 28.2 days).

\section{Growth}

Differences in body length between GM and UM-fed D. magna were not consistent among experiments (Fig. 3). In experiment 1 , significantly larger D. magna were found in the UM group at day $17(\boldsymbol{p}=\mathbf{0 . 0 5}, t$-test $)$. When testing the pooled data from all experiments at day 17 , and using Experiment as a covariate (i.e. correcting for differences between experiments), a tendency for larger individuals of D. magna feeding on UM-maize relative to the GM was found, yet the difference was not significant ( $p=0.134$, ANCOVA).

\section{Reproduction}

\section{Individual fecundity}

D. magna fed GM-maize had a significantly higher mean number of eggs per female in experiment 3 ( $\boldsymbol{p}=\mathbf{0 . 0 4 3}, t$-test). Also in the pooled samples from all experiments, GM-fed animals had a higher fecundity (7.3) compared to the UM-fed (5.1) (fig. 4), yet the difference was not statistically significant $(p=0.255$, ANCOVA).

Total production of eggs 
The total number of eggs produced by GM-fed D. magna was lower in sum for all the experiments, compared to those fed UM-maize (80 versus 96 eggs) (fig. 5), this was largely due to very few eggs produced in the GM experiment 1.

\section{Percentage of females reaching maturation}

The percentage of females that reached maturation (i.e. produced eggs) was generally lower in the GM-fed D. magna, ranging from 20-60\% in the different experiments $(36.7 \%$ on average) as compared to $50-80 \%$ (63.3\% on average) in the UM-fed D. magna (fig. 6). Statistically significant differences were found in experiment $3(\boldsymbol{p}=\mathbf{0 . 0 2 5}$, Chi-test $)$ and for the combined data from all experiments $(\boldsymbol{p}=\mathbf{0 . 0 3 9}$, Chi-test $)$.

\section{Age at maturation}

The age at $50 \%$ maturation was generally lower for the GM-fed D. magna (15.3 days) than for the UM-fed group (17.5 days) and the $95 \%$ confidence intervals estimated from bootstrapping did not overlap between the two groups (Fig. 7). 


\section{Discussion}

We detected negative effects of a transgenic Bt-maize line on fitness-related parameters of Daphnia magna in repeated and fully randomized laboratory experiments. Three repeated studies, with the same experimental design, lasted over the entire life-cycle of the test animals, allowing us to investigate impact on a number of life history traits.

Daphnia magna performed substantially better when fed the isogenic unmodified (UM) maize as compared to the GM-maize. The data pointed towards significantly reduced survival and a reduced proportion of females that reached maturity. These two variables are not independent as the ability to become sexually mature clearly depends on the survival. Small differences were found in growth rates, but there was a tendency for the UM-fed animals to have higher growth rates, and in one of the experiments (one out of six comparisons on adults) significantly larger body size was found in the UM-fed group compared with the group fed GM-maize. The individual fecundity showed a trend towards more eggs per female in the GM-fed group, and we observed a significantly higher fecundity in GM-fed animals in one of the experiments (one out of three). However, the overall reproductive output, i.e. the total number of egg produced, was higher in the UM-fed groups. The group fed GM-maize reproduced on average significantly earlier than D. magna fed UM-maize.

The above results allow identifying the likely mechanism behind the negative fitness response of D. magna fed GM-maize on the basis of expectations from life history theory corroborated by empirical data. The two mechanisms considered, limited nutrition versus low levels of toxicity, are expected to determine different configurations of life history traits. 
Reduced quantity as well as quality of food may lead to reduced clutch size and delayed reproduction in D. magna and D. longispina \{Brett, 1993807 /id;Enserink, 1995799 /id \} while only delayed reproduction was recorded for D. galeata (Vanni and Lampert 1992). Therefore, if the GM-maize in our experiments had a lower nutritional value than the UMmaize, we would expect $D$. magna to reproduce later and with smaller clutch sizes, i.e. the opposite of our observations.

On the other hand, low level toxicity is expected to reduce survival, a condition that, according to life history theory, might trigger greater investment in reproduction early in the life cycle (Roff 2002). For example, higher juvenile mortality is generally linked to an early onset of reproduction (Stearns and Koella 1986). In organisms with plastic life history traits, like D. magna \{Enserink, 1995799 /id \}, a response to low level toxicity may thus lead to an allocation of resources to increase the fecundity early in the life cycle (Twombly et al. 1998, Hansen et al. 1999, Mauri et al. 2003). At high levels of toxicity, the general development of the organisms is severely impaired and all reproductive characters are negatively affected, i.e. maturity is delayed and fecundity is reduced (Enserink et al. 1995, Hansen et al. 1999, Mauri et al. 2003).

In our experiments, D. magna fed GM-maize reproduced earlier and had higher individual fecundity as compared to D. magna fed UM-maize, but this was at the cost of survival and reproductive output later in life. From life history theory, our results are likely to be explained by an allocation trade-off after a toxic reaction (as opposed to reduced nutritional value) of $D$. magna to the GM-maize. 
Our data represent a food/feed quality test of one Cry1 Ab-transgenic versus the isogenic UMmaize variety grown in a specific environment. The strengths of the study include:

i) its specificity; the diet consisted of $100 \%$ maize. Other feeding studies using GM-feed have typically used diets of 60-76 \% from the transgenic material (Brake and Vlachos 1998, Ewen and Pusztai 1999, Reuter et al. 2002, Aeschbacher et al. 2005), sometimes as low as 25-33\% (Teshima et al. 2002, Hammond et al. 2006). On the other hand, dozens of studies on terrestrial arthropods (D. magna is an arthropod) have used $100 \%$ plant diets to test impacts of transgenic plants, mostly related to Bt-plants (reviewed in Lövei and Arpaia (2005)). A summary of these studies show that $57 \%$ of the studies have significant negative impacts from the transgenic Bt-plants (Lövei and Arpaia 2005);

ii) its duration, through the whole life cycle of the animal; within 30 hours after birth to and up to a maximum of six reproductive events. Young and growing animals are likely to be more sensitive to food quality as compared to adults since a healthy development depends on appropriate nutrition. Possible negative health effects of GM-foods have been shown in young rats (Ewen and Pusztai 1999, Pusztai 2002), in studies that have been criticized and discussed in great detail, but unfortunately not repeated. However, recent European regulations recognize the need for long-term feeding studies with and without spiking with the pure novel gene product (Knudsen and Poulsen 2007);

iii) its study design, with complete randomization (that corrects for potentially confounding factors in the experimental set-up), lack of interactions between the experimental units (all experimental animals were independent of each other), double blind measurements of body length (i.e. the measurements were done without knowledge of which treatment group each animal belonged to), in a well known model animal with minimal genetic variation (clonal), and with several fitness traits tested. 
These strengths can also be seen as limitations; specificity comes at the cost of generality: i) only one species/variety/hybrid of GM-plant and it's UM counterpart was used; ii) these were grown in only one type of environment; iii) only one type of model organisms was used.

However, more that anything else these limitations point to the need of further studies: different varieties of different transgenic plants grown under a wide variety of environmental conditions should be tested with a comprehensive methodology. A reasonable test regime for genetically modified organisms must be based on a case by case approach (Kowalchuk et al. 2003), as also recognized by more than 140 countries committed to implementation of the Cartagena Protocol on Biosafety (Hill and Sendashonga 2006).

A natural follow-up of the present study would be to investigate dose-responses of Bt-toxin on D. magna. At first sight the Cry1Ab toxin seems to be the most likely cause of the reduced performance of the GM-maize-fed D. magna. However, the relatively modest expression level of the transgenic product in our test maize $(67+/-27$ ng Cry1 Ab toxin per gram dried kernels), which is lower than what is usually found even in pollen ( $<90 \mathrm{ng}$ per gram) (www.agbios.com), may indicate that some other difference exists between the tested GMmaize and it's UM isoline. An interesting observation in our study is that the GM-maize contained Bt-toxin (though at a modest level) after more than three years in storage, indicating that Cry1 $\mathrm{Ab}$ toxin is not effectively broken down in dried maize kernels.

In these feeding trials, we used maize as the sole food source. D.magna can survive on a multitude of diets, but admittedly this is an artificial situation. However our study was not aimed at estimating the responses of D. magna under natural field conditions, where they would have a diverse diet. The intention was to perform an initial screening of potential Bt- 
maize effects on a non-target organism. The results indicate that D. magna, and potentially also other related aquatic zooplankton species, may be vulnerable to transgenic Cry1Abmaize. While the causality of the observed effects still remains open, our results go along with others (Lövei and Arpaia 2005, Hilbeck and Schmidt 2006, Rosi-Marshall et al. 2007) and call for further testing of non-target arthropods under varying conditions. Summary data from both the U.S. and Europe indicate that the expression of Bt-toxin is 20-30 times higher in maize leaves as compared to maize grains (http://www.agbios.com). If Cry1 Ab toxin caused the effects on D. magna observed in this study, the considerably higher amount of expressed transgenic protein from the rest of the plant will have a larger potential to reach and affect non-target organisms in the environment.

The large biomass of dead plants/roots that is left in the field after harvest represents a huge amount of exotic and potentially bioactive components for recipient ecosystems. Bt-toxin produced in GM plants has been shown to retain $25-30 \%$ of its toxicity after 140 days when bound to soil (Palm et al. 1996). Adsorption and binding of Cry proteins to clay sometimes even enhance the insecticidal activity (Tapp and Stotzky 1995), thus increasing the likelihood that bioactive toxin is accumulated in the environment (Groot and Dicke 2002). At the same time, Bt-maize and isogenic controls have been corroborated to be substantially equivalent at the level of major nutrients and minerals and trace elements, both in kernels (Brake and Vlachos 1998, Sidhu et al. 2000) and in the whole plant (Clark and Ipharraguerre 2001). Clark and co-workers found a negative trend in growth for the terrestrial isopod Trachelipus rathkii when fed different Bt-maize varieties compared to their isolines, but they could not find any negative effect of even high concentrations of purified bacterial Bt-toxin on the same testorganism (Clark et al. 2006). There are several possible explanations for such findings: i) The Bt-toxin in the plant is different from the purified, bacterial version, due to, for instance, plant 
specific post-translational modifications; ii) the nutritional quality of the transgenic plant and the UM isoline tissues are different, due to, for instance, overexpressed anti-nutrional factors; iii) some other difference(s) exist(s) between the GM and the isoline, due to, for instance, insertional effects on the expression levels of endogenous genes.

In conclusion, our study demonstrated significant and negative long-term effects after feeding a transgenic Bt-maize variety. The combination of life history traits indicates a toxic response of $D$. magna to the GM-maize. Within our test system, we reject the null hypothesis that the tested GM-maize and UM-maize had the same quality as a food source. The observed effects of transgenic Bt-maize on D. magna call for greater attention, not only on the run off material from transgenic agricultural fields, but also on the sensitivity of aquatic non-target organisms to transgenic products.

\section{Acknowledgements}

We would like to thank Dr. Chito Medina and farmers from the Iloilo district in the Philippines, for providing the maize samples used in the experiments. We are grateful to Professor Kaare M. Nielsen for valuable discussions related to the experiments. We also thank Dr. Idun Grønsberg, Marte Albrigtsen, Julia Eggert, and Elisabeth Olsen at the GenØk Lab in Troms $\varnothing$, and to Dr. Morten Johansen and Kriss Rokkan Iversen at the Norwegian College of Fishery Science for practical assistance during the experiments. The studies were supported by a grant (project no. 154504) from the Research Council of Norway. 


\section{Figure captions}

Figure 1. Survival curves (\%) of D. magna fed on GM-maize (dotted line) and UM-maize (solid line) in experiment 1, 2 and 3 (from top to bottom).

Figure 2. Proportion of surviving D. magna fed on GM-maize (dotted lines) and UM-maize (solid lines) for pooled data $(\mathrm{n}=60)$. Thin lines represent $95 \%$ confidence intervals.

Figure 3. Body size at day 1, 2, 9, 17, 29 and 42 of D. magna fed on GM-maize and UMmaize in the three different experiments. The $p$-value of a significant difference within experiment 1 is shown ( $t$-test).

Figure 4. Mean number of eggs (+/- 95\% confidence intervals) per female $D$. magna fed on GM-maize and UM-maize in experiments 1,2, 3 and for all of them combined. The $p$-value of a significant difference within experiment 3 is shown ( $t$-test)

Figure 5. Total number of eggs observed in D. magna fed on GM-maize and UM-maize in experiments 1, 2, 3 and for all of them combined (total sum).

Figure 6. Proportion of females that reached maturation in D. magna fed on GM-maize and UM-maize in experiments $1,2,3$ and for all of them combined. $P$-values of significant differences (within experiment 3 and for the pooled samples) are shown (Chi-square test).

Figure 7. Age at 50\% maturation (+/- 95\% confidence intervals) for D. magna fed GM-maize and UM-maize. Confidence intervals were calculated from bootstrapping. 

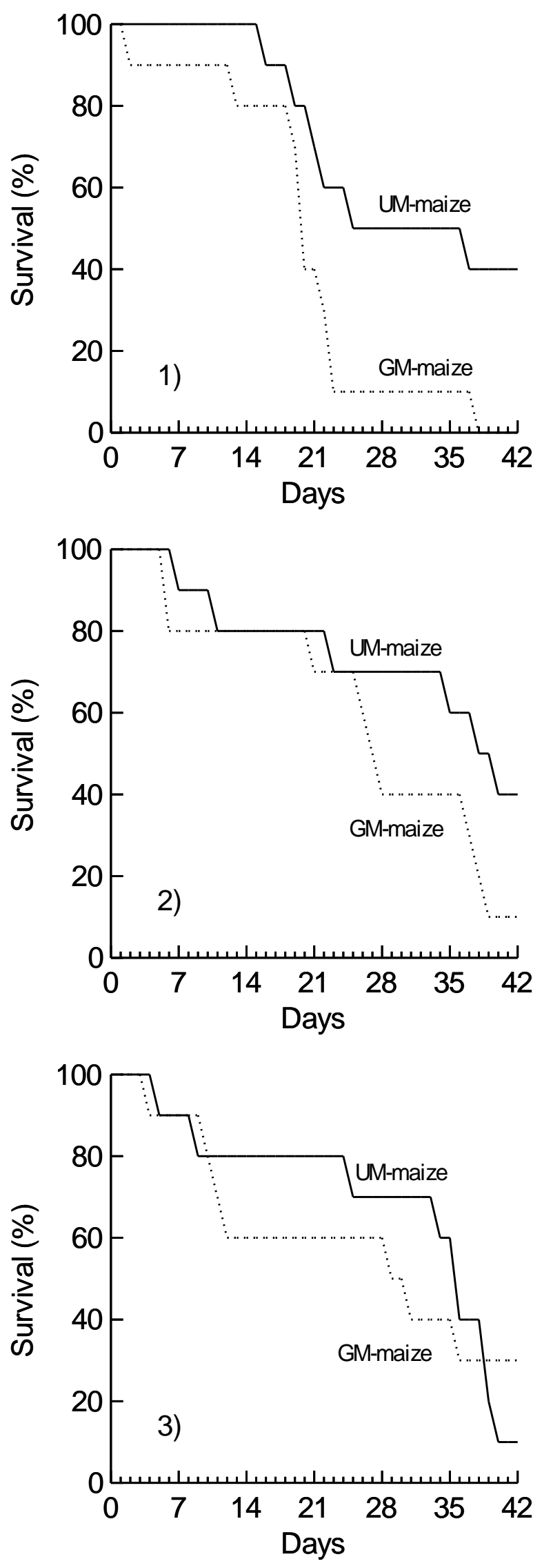

Figure 1 


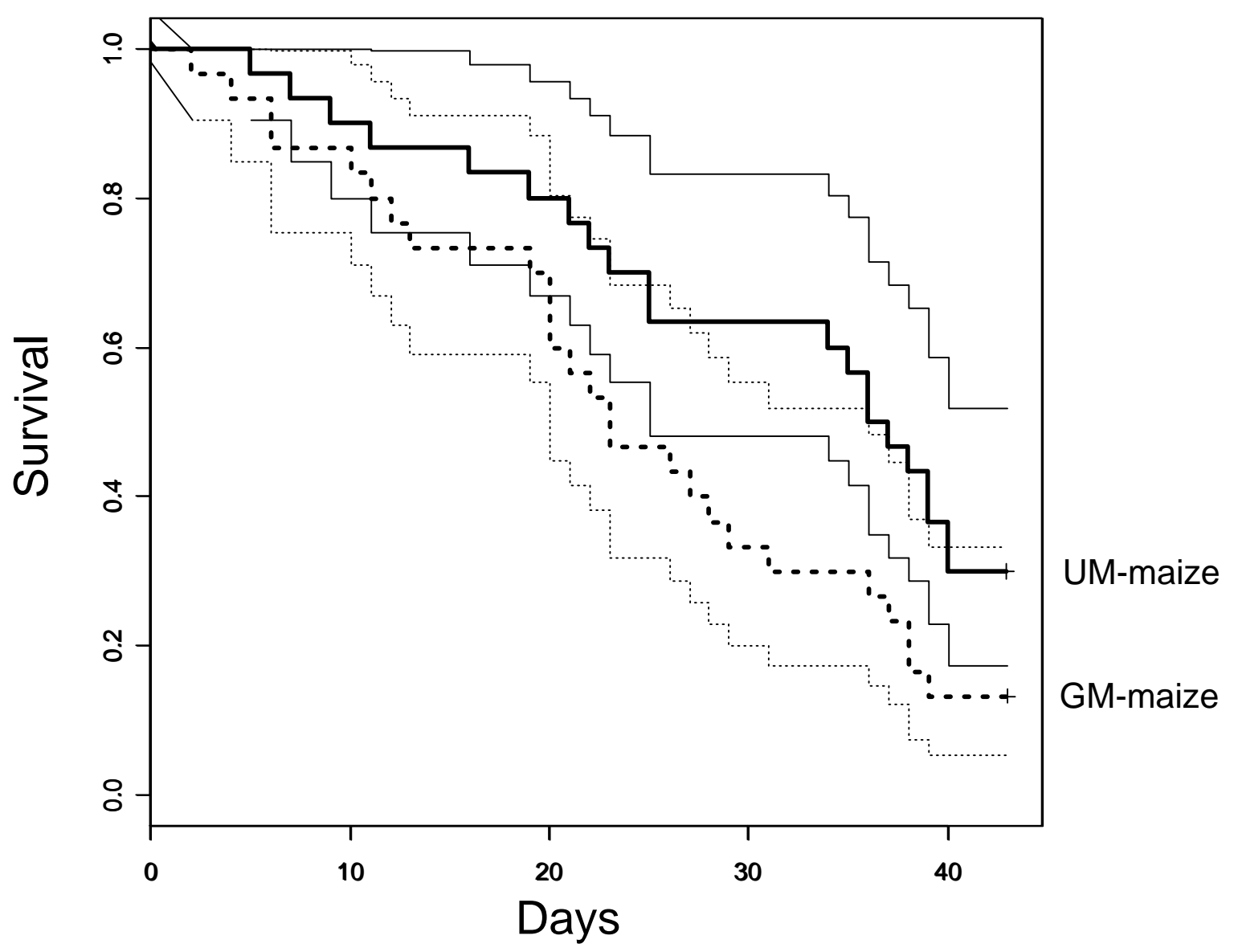

Figure 2. 

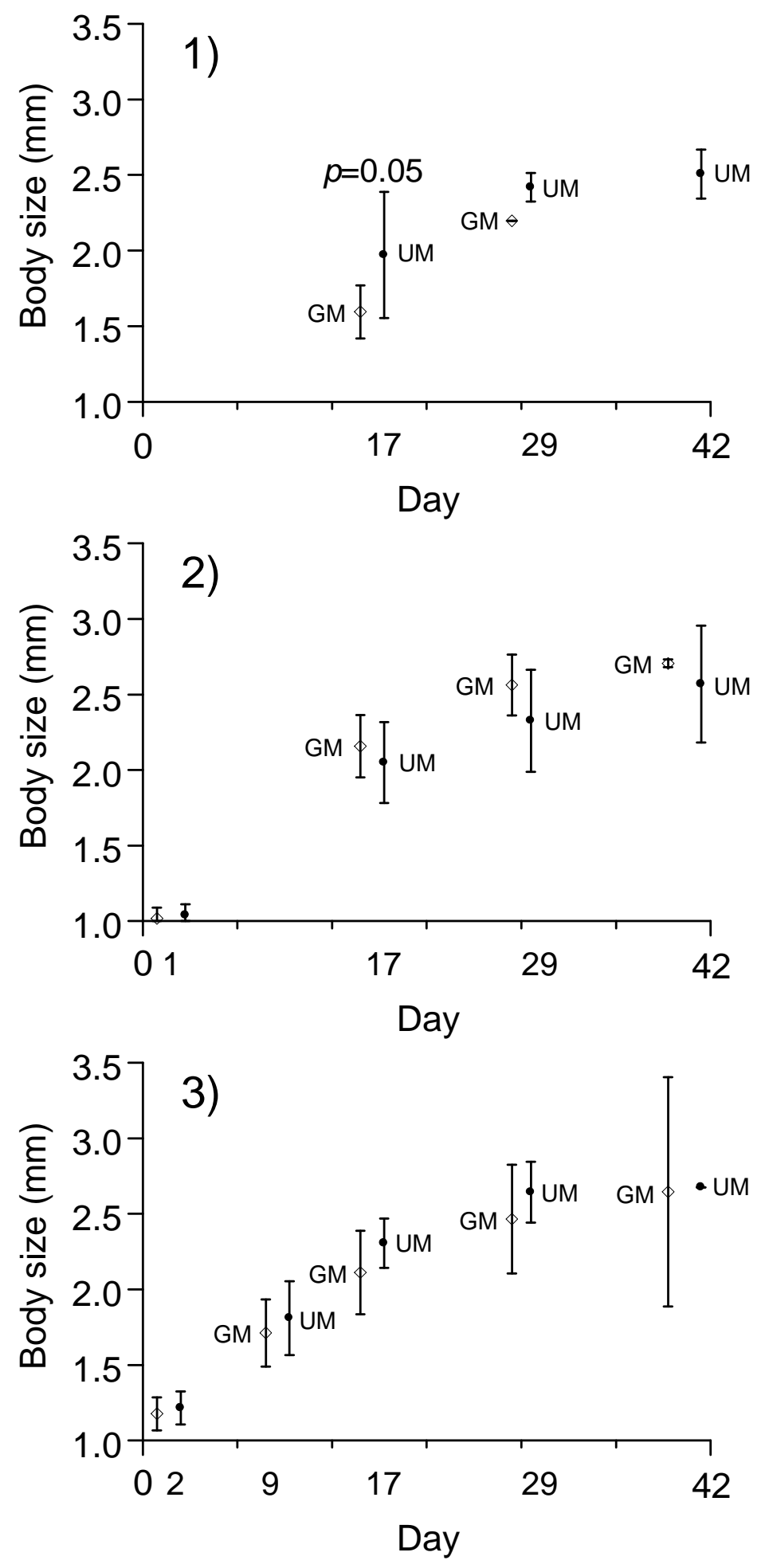

Figure 3 


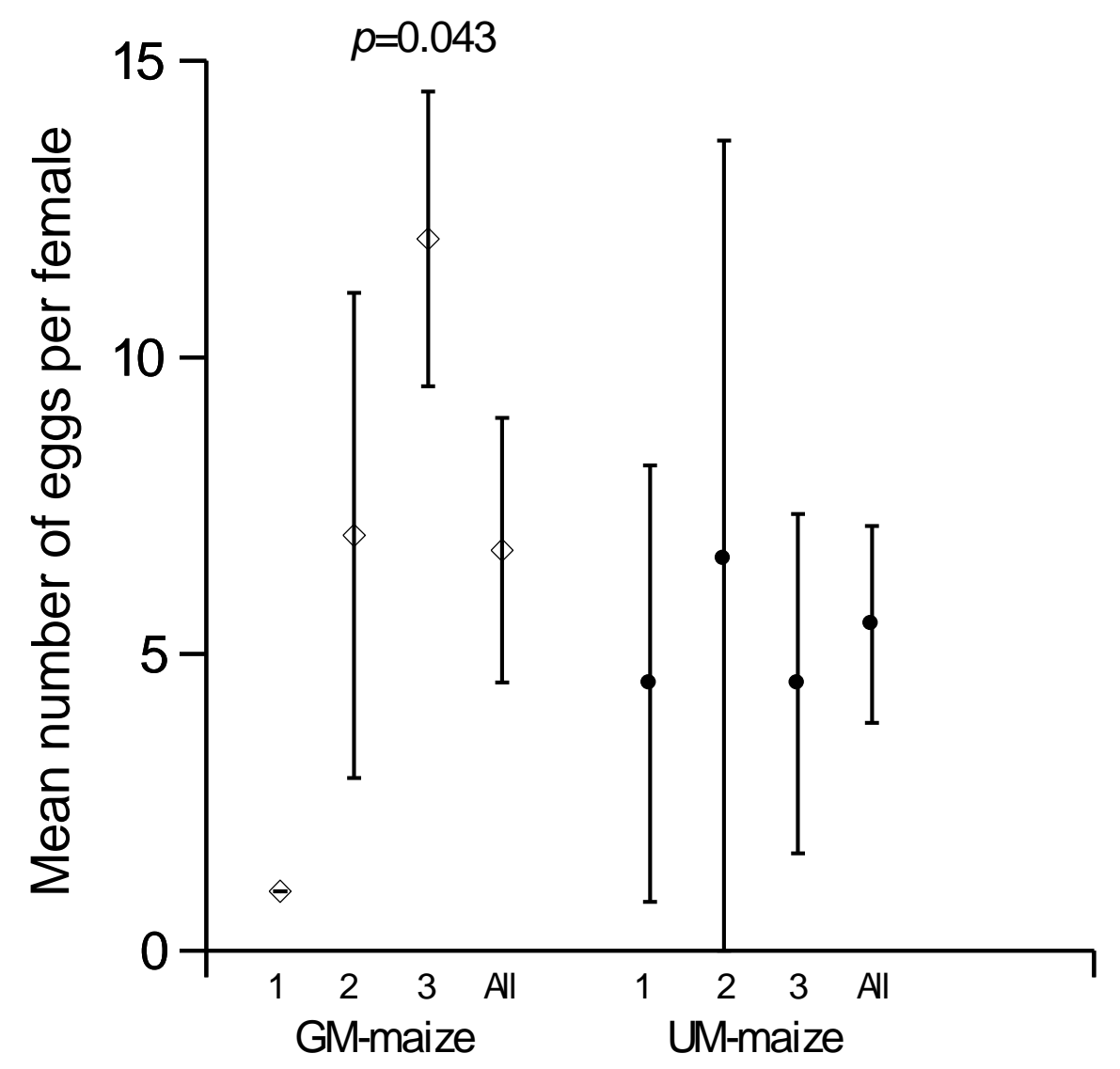

Figure 4. 


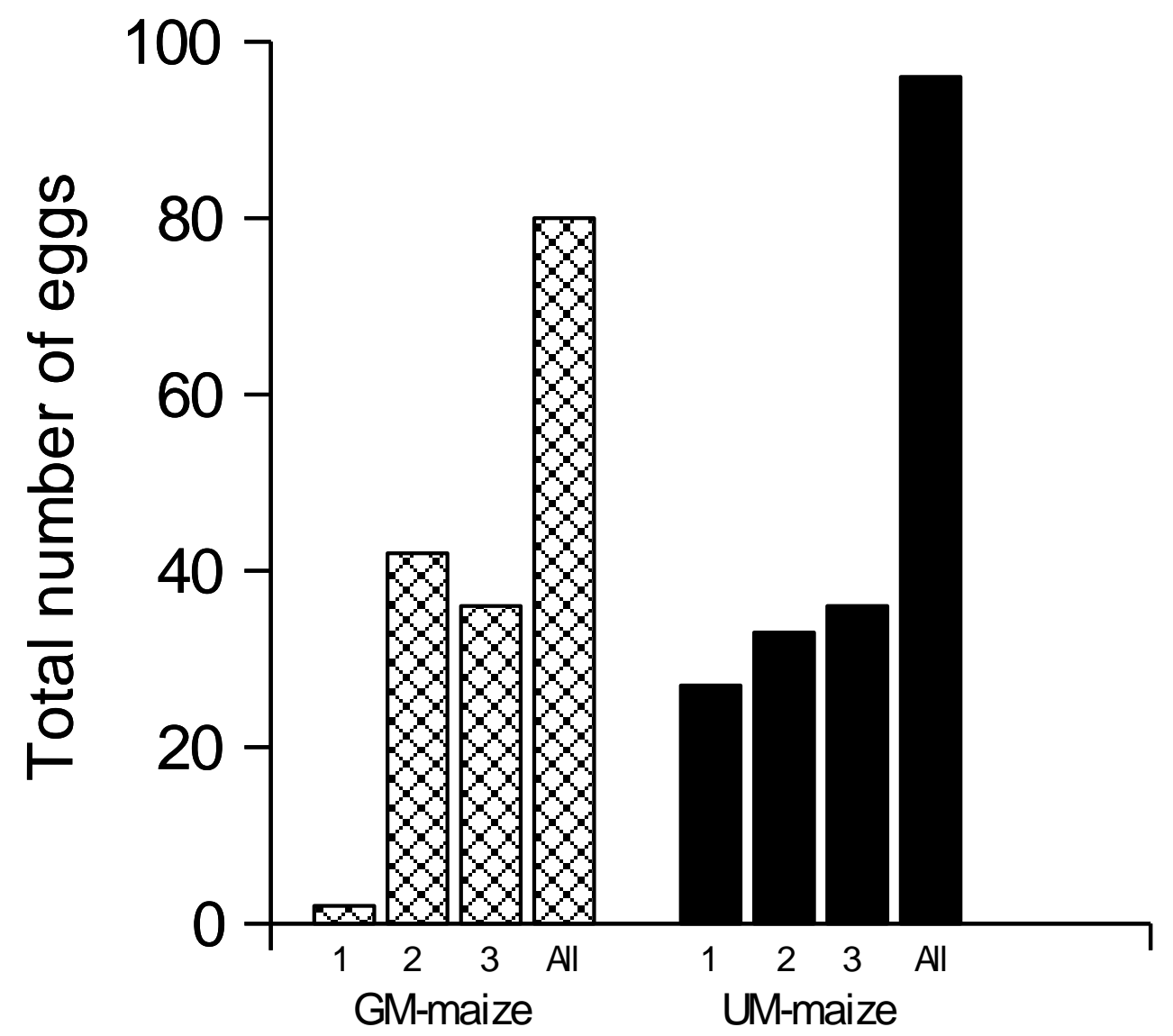

Figure 5. 


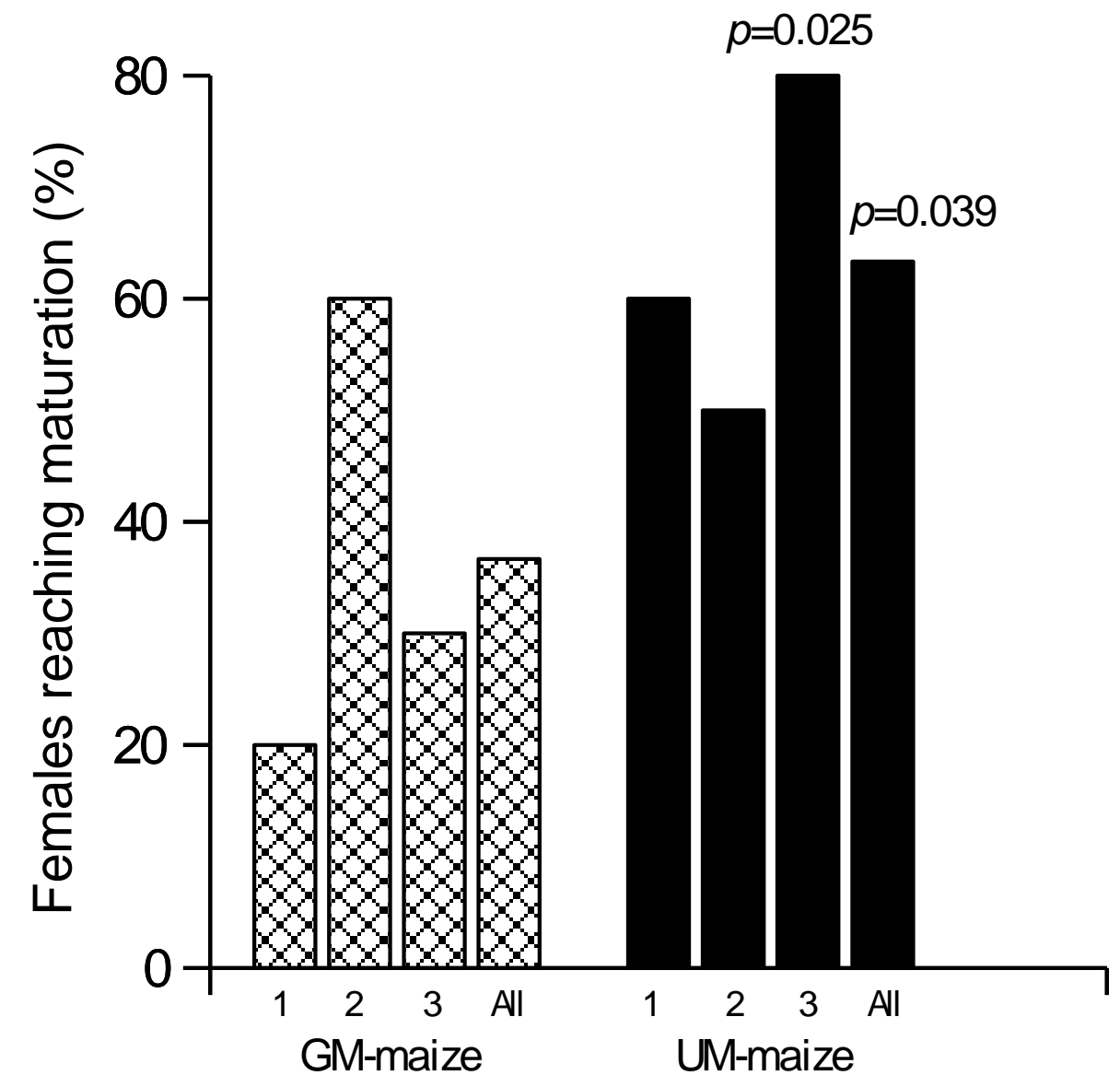

Figure 6. 


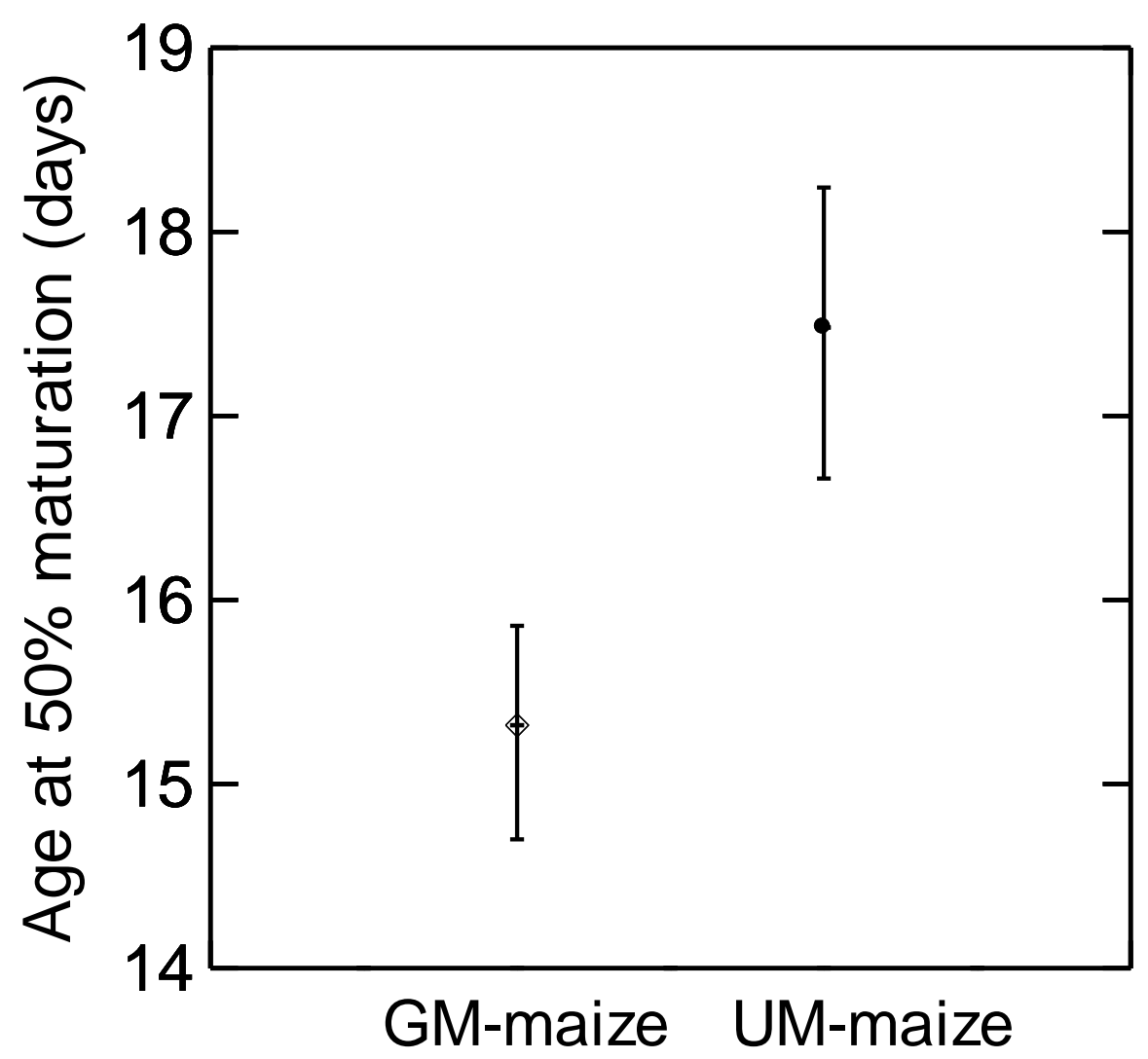

Figure 7. 
References

Aeschbacher K, Messikommer R, Meile L, Wenk C. Bt176 corn in poultry nutrition: Physiological characteristics and fate of recombinant plant DNA in chickens. Poultry Science 84[3], 385-394. 2005.

Andow D, Hilbeck A. Science-based risk assessment for nontarget effects of transgenic crops. Bioscience 54[7], 637-649. 2004.

Atienzar FA, Cheung VV, vadesh NJ, epledge MH. Fitness parameters and DNA effects are sensitive indicators of copper-induced toxicity in Daphnia magna. Toxicological Sciences 59, 241-250. 2001.

Barry MJ. Effects of an organochlorine pesticide on different levels of organization in Daphnia. Ecotoxicology and Environmental Safety. Environmental Safety 34, 239-251. 1996.

Brake J, Vlachos D. Evaluation of transgenic event 176 "Bt" corn in broiler chickens. Poultry Science 77[5], 648-653. 1998.

Brandt SL, Coudron TA, Habibi J, Brown GR, Ooagan OM, Wagner RM, Wright MK, Backus EA, Huesing JE. Interaction of two Bacillus thuringiensis delta-endotoxins with the digestive system of lygus hesperus. Current Microbiology 48[1], 1-9. 2004.

Bravo A, Gill SS, Soberon M. Mode of action of Bacillus thuringiensis Cry and Cyt toxins and their potential for insect control. Toxicon 49, 423-435. 2007.

Brett MT. Resource Quality Effects on Daphnia-Longispina Offspring Fitness. J Plankton Res 15[4], 403-412. 1993.

Campbell AK, Wann KT, Matthews SB. Lactose causes heart arrhythmia in the water flea Daphnia pulex. Comparative Biochemistry and Physiology B-Biochemistry \& Molecular Biology 139[2], 225-234. 2004.

Clark BW, Prihoda KR, Coats JR. Subacute effects of transgenic Cry1Ab Bacillus thuringiensis corn litter on the isopods Trachelipus rathkii and Armadillidium nasatum. Environmental Toxicology and Chemistry 25[10], 2653-2661. 2006.

Clark JH, Ipharraguerre IR. Biotech crops as feeds for livestock. Abstracts of Papers of the American Chemical Society 222, U67. 2001. 
Crickmore N. Using worms to better understand how Bacillus thuringiensis kills insects. Trends in Microbiology 13[8], 347-350. 2005.

Domingo JL. Toxicity studies of genetically modified plants: a review of the published literature. Critical Reviews in Food Science and Nutrition 47, 721-733. 2007.

Douville M, Gagne F, Blaise C, Andre C. Occurence and persistence of Bacillus thuringiensis (Bt) and transgenic Bt corn crylAb gene from an aquatic environment. Ecotoxicology and Environmental Safety 66, 195-203. 2007.

Dutton A, Romeis J, Bigler F. Assessing the risks of insect resistant transgenic plants on entomophagous arthropods: Bt-maize expressing Cry1 Ab as a case study. Biocontrol 48[6], 611-636. 2003.

Dutton A, Romeis J, Bigler F. Effects of Bt maize expressing Cry1 Ab and Bt spray on Spodoptera littoralis. Entomologia Experimentalis et Applicata 114[3], 161-169. 2005.

Enserink EL, Kerkhofs MJJ, Baltus CAM, Koeman JH. Influence of Food Quantity and LeadExposure on Maturation in Daphnia-Magna - Evidence for A Trade-Off Mechanism. Funct Ecol 9[2], 175-185. 1995.

Ewen SWB, Pusztai A. Effect of diets containing genetically modified potatoes expressing Galanthus nivalis lectin on rat small intestine. Lancet 354[9187], 1353-1354. 1999.

Groot AT, Dicke M. Insect-resistant transgenic plants in a multi-trophic context. Plant Journal 31[4], 387-406. 2002.

Hammond BG, Dudek R, Lemen JK, Nemeth MA. Results of a 90-day safety assurance study with rats fed grain from corn borer-protected corn. Food and Chemical Toxicology 44[7], 1092-1099. 2006.

Hansen FT, Forbes VE, Forbes TL. Effects of 4-n-nonylphenol on life-history traits and population dynamics of a polychaete. Ecol Appl 9[2], 482-495. 1999.

Hilbeck A. Implications of transgenic, insecticidal plants for insect and plant biodiversity. Perspectives in Plant Ecology Evolution and Systematics 4[1], 43-61. 2001.

Hilbeck A, Schmidt JEU. Another view on Bt proteins - how specific are they and what else might they do? Biopestic Int 2[1], 1-50. 2006. 
Hill R, Sendashonga C. Conservation biology, genetically modified organisms and the biosafety protocol. Conserv Biol 20[6], 1620-1625. 2006.

James C. Global status of commercialized biotech/GM crops: 2006. ISAAA Brief No. 35. 2006. ISAAA: Ithaca, NY.

Kluttgen B, Dulmer U, Engels M, Ratte HT. Adam, An Artificial Fresh-Water for the Culture of Zooplankton. Water Research 28[3], 743-746. 1994.

Knudsen I, Poulsen M. Comparative safety testing of genetically modified foods in a 90-day rat feeding study design allowing the distinction between primary and secondary effects of the new genetic event. Regulatory Toxicology and Pharmacology 49[1], 53-62. 2007.

Kowalchuk GA, Bruinsma M, van Veen JA. Assessing responses of soil microorganisms to GM plants. Trends Ecol Evol 18[8], 403-410. 2003.

Kramer KJM, Jak RG, van Hattum B, Hooftman RN, Zwolsman JJG. Copper toxicity in relation to surface water-dissolved organic matter: Biological effects to Daphnia magna. Environmental Toxicology and Chemistry 23[12], 2971-2980. 2004.

Lövei GL, Arpaia S. The impact of transgenic plants on natural enemies: a critical review of laboratory studies. Entomologia Experimentalis et Applicata 114, 1-14. 2005.

Mauri M, Baraldi E, Simonini R. Effects of zinc exposure on the polychaete Dinophilus gyrociliatus: a life-table response experiment. Aquatic Toxicology 65[1], 93-100. 2003.

Mendelson M, Kough J, Vaituzis Z, Matthews K. Are Bt crops safe? Nature Biotechnology 21[9], 1003-1009. 2003.

Nogueira ICG, Saker ML, Pflugmacher S, Wiegand C, Vasconcelos VM. Toxicity of the Cyanobacterium Cylindrospermopsis raciborskii to Daphnia magna . Environ Toxicol 19, 453-459. 2004.

O'Callaghan M, Glare TR, Burgess EPJ, Malone LA. Effects of plants genetically modified for insect resistance on nontarget organisms. Annual Review of Entomology 50, 271-292. 2005.

Palm CJ, Schaller DL, Donegan KK, Seidler RJ. Persistence in soil of transgenic plant produced Bacillus thuringiensis var kurstaki delta-endotoxin. Canadian Journal of Microbiology 42[12], 1258-1262. 1996. 
Pusztai A. Can science give us the tools for recognizing possible health risks of GM food? Nutrition and health 16,73-84. 2002.

Reuter T, Aulrich K, Berk A, Flachowsky G. Investigations on genetically modified maize (Bt-maize) in pig nutrition: Chemical composition and nutritional evaluation. Archives of Animal Nutrition-Archiv fur Tierernahrung 56[1], 23-31. 2002.

Roff DA. Life history evolution. 1-527. 2002. Massachusetts, Sinauer Associates, Sunderland.

Rosi-Marshall EJ, Tank JL, Royer TV, Whiles MR, Evans-White M, Chambers C, Griffiths NA, Pokelsek J, Stephen ML. Toxins in transgenic crop byproducts may affect headwater stream ecosystems. Proc Natl Acad Sci U S A 104[41], 16204-16208. 2007.

Sidhu RS, Hammond BG, Fuchs RL, Mutz JN, Holden LR, George B, Olson T. Glyphosatetolerant corn: The composition and feeding value of grain from glyphosate-tolerant corn is equivalent to that of conventional corn (Zea mays L.). Journal of Agricultural and Food Chemistry 48[6], 2305-2312. 2000.

Sims IR, Watson S, Holmes D. Toward a standard Daphnia juvenile production test. Environmental Toxicology and Chemistry 12[11], 2053-2058. 1993.

Stark JD, Banks JE. Population-level effects of pesticides and other toxicants on arthropods. Annual Review of Entomology 48, 505-519. 2003.

Stearns SC, Koella JC. The evolution of phenotypic plasticity in life-history traits: predictions of reaction norms for age and size at maturity. Evolution 40[5], 893-913. 1986.

Tapp H, Stotzky G. Insecticidal Activity of the Toxins from Bacillus-Thuringiensis Subspecies Kurstaki and Tenebrionis Adsorbed and Bound on Pure and Soil Clays. Applied and Environmental Microbiology 61[5], 1786-1790. 1995.

Teshima R, Watanabe T, Okunuki H, Isuzugawa K, Akiyama H, Onodera H, Imai T, Toyoda M, Sawada J. Effect of subchronic feeding of genetically modified corn (CBH351) on immune system in BN rats and B10A mice. Journal of the Food Hygienic Society of Japan 43[5], 273-279. 2002.

Twombly S, Clancy N, Burns CW. Life history consequences of food quality in the freshwater copepod Boeckella triarticulata. Ecology 79[5], 1711-1724. 1998.

Vanni MJ, Lampert W. Food Quality Effects on Life-History Traits and Fitness in the Generalist Herbivore Daphnia. Oecologia 92[1], 48-57. 1992. 